\title{
Pengaruh Perlakuan Hardenability dan Tempering pada Kekuatan Tarik dan Kekuatan Impak Baja E335
}

\author{
Muhammad Budi Haryono ${ }^{1}$ dan Wikan Budi Utami ${ }^{2}$ \\ ${ }^{1}$ Teknik Mesin, Universitas Pancasakti Tegal \\ ${ }^{2}$ Pendidikan Matematika, Universitas Pancasakti Tegal \\ Jalan Halmahera KM.1. Tegal, 52121 \\ Telp.: (0283) 351082 \\ E-mail: haryono.upstegal@gmail.com
}

\begin{abstract}
Hardenability has more attention because it makes the material stronger and has good ductility. This study aims to investigate the treatment of quenching (water, brine and lime water) on the mechanical properties of steel E355. In this study E355 steel was heated at Hoffman furnace with temperature $880^{\circ} \mathrm{C}$ for 2 hours, after that each material was dipped into different cooling medium then tempered at $600{ }^{\circ} \mathrm{C}$ for 2 hours. The last stage of material characterization include tensile strength and impact strength. The results obtained with lime water cooling medium have better tensile strength and toughness.
\end{abstract}

Keywords: Hardenability,tempering, E355 steel, Tensile Strength, Impak Strength.

\section{Abstrak}

Hardenability memiliki perhatian lebih dikarenakan membuat material lebih kuat dan memiliki keuletan yang baik. Penelitian ini bertujuan menginvestigasi perlakuan quenching (air,air garam dan air kapur) terhadap sifat mekanik baja E355. Pada penelitian ini baja E355 dipanakan pada tungku Hoffman dengan temperatur $880^{\circ} \mathrm{C}$ selama 2 jam, setelah itu setiap material dicelupkan ke media pendingin yang berbeda lalu dilakukan tempering pada temperatur $600^{\circ} \mathrm{C}$ selama 2 jam.Tahap terakhir karakterisasi material meliputi kekuatan tarik dan kekuatan impak. Hasil yang didapatkan dengan media pendingin kapur memiliki kekuatan tarik dan ketangguhan yang lebih baik.

Keywords: Hardenability,tempering, baja E355, Kekuatan Tarik, Kekuatan Impak

\section{PENDAHULUAN}

Pada industri otomotif sekarang ini, design kendaraan dibuat ringan, standar keselatam yang tinggi dan dampak lingkungan yang lebih rendah [Panich, 2013]. Peran material merupakan kombinasi antara kekuatan dan keuletan, oleh karena itu akan merungangi ketebalan dari komponen tanpa mengurangi standar keselamatan [Bouaziz, 2013].

Sifat mekanik seperti keuletan, ketangguhan, kekuatan, kekerasan dan kekuatan tarik sangat mudah dimodifikasi dengan perlakuan panas pada baja karbon sedang. Kekuatan tarik yang dihasilkan oleh baja karbon rendah dapat diperoleh dari variasi perlakuan panas seperti annealing, normalizing, hardening dan tempering [Sentilkumar, 2012]. Kekuatan mekanik material dapat meningkat dengan pengontrolan perlakuan panas dan proses pendinginan [Pardeep, 2014].

Proses perlakuan panas meliputi pemanasan baja pada suhu tertentu, dipertahankan pada waktu tertentu dan didinginkan pada media tertentu pula. Perlakuan panas mempunyai tujuan untuk meningkatkan keuletan, menghilangkan tegangan internal, menghaluskan butir kristal, meningkatkan kekerasan, tegangan tarik logam dan sejenisnya. Tujuan tersebut akan tercapai jika memperhatikan faktor yang mempengaruhinya, seperti suhu pemanasan dan media pendingin yang digunakan (Djafrie, 1983).

Untuk Menghasilkan suatu produk yang menuntut keuletan dan ketahanan terhadap gesekan perlu dilakukan proses pemanasan ulang atau temper. Tujuan dari penemperan adalah untuk meningkatkan keuletan dan mengurangi kerapuhan. Pengaruh dari suhu temper ini akan menurunkan sifat ketahanan dari bahan terhadap penekanan. [Arief, 2012].

Proses tempering dapat menaikkan kekuatan tarik baja AISI 4140. Pada akhir proses penelitian kenaikan kekuatan tarik sebesar 4,12\% dari logam induk, Selain itu, tempering dapat menurunkan keuletan baja AISI 4140. Pada akhir proses penelitian penurunan keuletan baja AISI 4140 sebesar 18,5\% dari logam induk [Williyanto, 2008).

Berbagai bahan pendingin yang digunakan dalam proses perlakuan panas antara lain [Lagiyono,2011]: 
a. Air

Pendinginan dengan menggunakan air akan memberikan daya pendinginan yang cepat. Biasanya ke dalam air tersebut dilarutkan garam dapur sebagai usaha mempercepat turunnya temperatur benda kerja dan mengakibatkan bahan menjadi keras.

b. Minyak

Minyak yang digunakan sebagai fluida pendingin dalam perlakuan panas adalah yang dapat memberikan lapisan karbon pada kulit (permukaan) benda kerja yang diolah. Selain minyak yang khusus digunakan sebagai bahan pendingin pada proses perlakuan panas, dapat juga digunakan minyak bakar atau solar.

c. Udara

Pendinginan udara dilakukan untuk perlakuan panas yang membutuhkan pendinginan lambat. Udara sebagai pendingin akan memberikan kesempatan kepada logam untuk membentuk kristal - kristal dan kemungkinan mengikat unsur - unsur lain dari udara.

d. Garam

Garam dipakai sebagai bahan pendingin disebabkan memiliki sifat mendinginkan yang teratur dan cepat.

e. Kapur

Kapur adalah kapur non hidrolik dengan kadar Kalsiummonoxida yang tinggi jika berupa kapur tohor ( belum berhubungan dengan air ) atau mengandung banyak kalsium hydroxide jika telah disiram ( direndam dengan air )

Kemampuan suatu jenis media dalam mendinginkan spesimen berbeda sehingga akan disesuaikan dengan tujuan dari material akan dipakai.

Quenching dengan perbedaan media pendingin austenite menjadi martensit, perubahan sifat elemen paduan dapan mempengaruhi hardenability [Smallman, 2007]. Pengaruh heat treatmen pada sifat mekanik AISI1040 diinvestigasi. Hasil yang ditujukan terjadi penurunan kekuatan tarik dan keuletan tetapi elongi meningkat dengan meningkatnya temperatur dan waktu tempering. Kekerasan spesimen menurun dengan meningkatnya temperatur dan waktu tempering. [Ashishiverma, 2013].

Investigasi pada efek heat treatmen pada sifat mekanik material SAE 1040 dengan media quenching air memiliki kekerasan maksimum dengan didukung proses tempering [Pardeep, 2014]. Pendinginan menggunakan air merupakan salah satu cara metode pendinginan cepat kuat dan ekonomis [Zeyad, 2016].

Pada investigasi pengaruh air garam pada AISI
304, dengan kandungan garam 30\% menghasilkan kekuatan tarik dan kekerasan yang lebih baik, dengan pertambahan kadar garam akan menurunkan kekuatan tarik dan kekerasan [Salleh, 2013]. Pengaruh quenching dengan media kapur memiliki keuletan yang lebih tinggi dari pada menggunakan media air maupun udara [Lagiyono,2011].

Pada penelitian ini ini akan dibahas pengaruh media quenching terhadap sifat mekanik baja E355. Sifat mekanik yang akan dibandingkan adalah kekuatan tarik dan kekuatan Impak Selanjutnya hasil pengujian sifat mekanik akan dibandingkan.

\section{METODE}

Gambar 1 menunjukan proses hardenability dan tempering pada baja E355. Baja E355 dipanaskan pada tungku Hoffman (Gambar 2) hingga fasa austenit pada temperatur $880^{\circ} \mathrm{C}$ ditahan selama 2 jam. Setelah material mencapai fasa austenit secara keseluruhan, material di quenching pada media pendingin yang berbeda-beda (air, air garam dan air kapur dengan kosentrasi 30\%). Setelah mengalami proses quenching, material di panaskan kembali pada temperatur $600^{\circ} \mathrm{C}$. Selanjutnya dilakukan karakterisasi material meliputi kekuatan tarik dan kekuatan impak, tahapan penelitian dapat dilihat pada gambar 3. Pengujian tarik menggunakan standart ASTM E-8 dan Pengujian impak charpy dengan standart ASTM E-23.

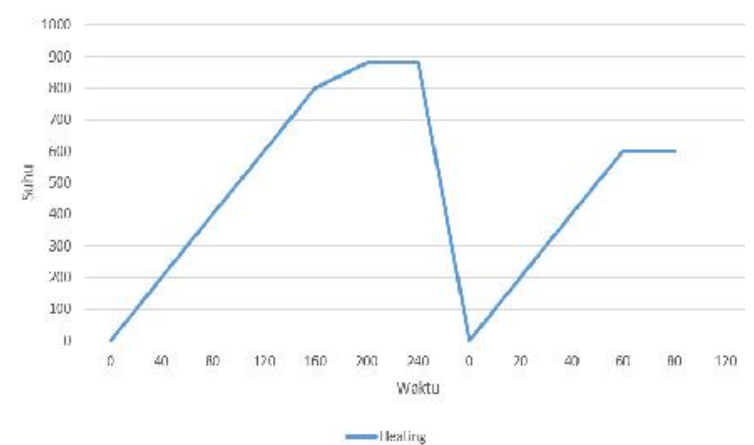

Gambar 1. Proses hardenability dan tempering pada baja E355 (waktu vs suhu) 


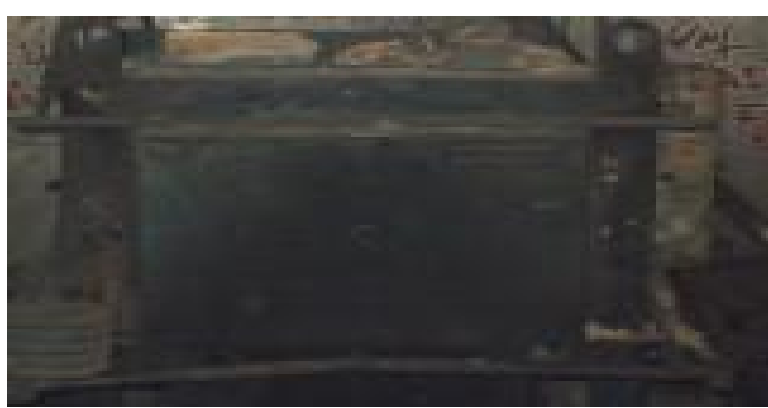

Gambar 2. Tungku Hoffman.

Tabel 1. Komposisi Kimia E355.

\begin{tabular}{c|c|c|c}
$\mathrm{Fe}$ & $\mathrm{C}$ & $\mathrm{Mn}$ & Sisa \\
\hline $98,2 \%$ & $0,442 \%$ & $0,71 \%$ & $0,6 \%$
\end{tabular}

Tabel 2. Variasi Hardenability.

\begin{tabular}{|c|c|c|c|}
\hline No & $\begin{array}{l}\text { Pemanasan } \\
\left({ }^{\circ} \mathrm{C}\right)\end{array}$ & Pencelupan & $\begin{array}{l}\text { Pemanasan } \\
\left({ }^{\circ} \mathrm{C}\right)\end{array}$ \\
\hline \multicolumn{4}{|l|}{ Air } \\
\hline $1,2,3$ & 880 & 30 detik & 600 \\
\hline \multicolumn{4}{|c|}{ Air Garam } \\
\hline $1,2,3$ & 880 & 30 detik & 600 \\
\hline \multicolumn{4}{|c|}{ Air Kapur } \\
\hline $1,2,3$ & 880 & 30 detik & 600 \\
\hline
\end{tabular}

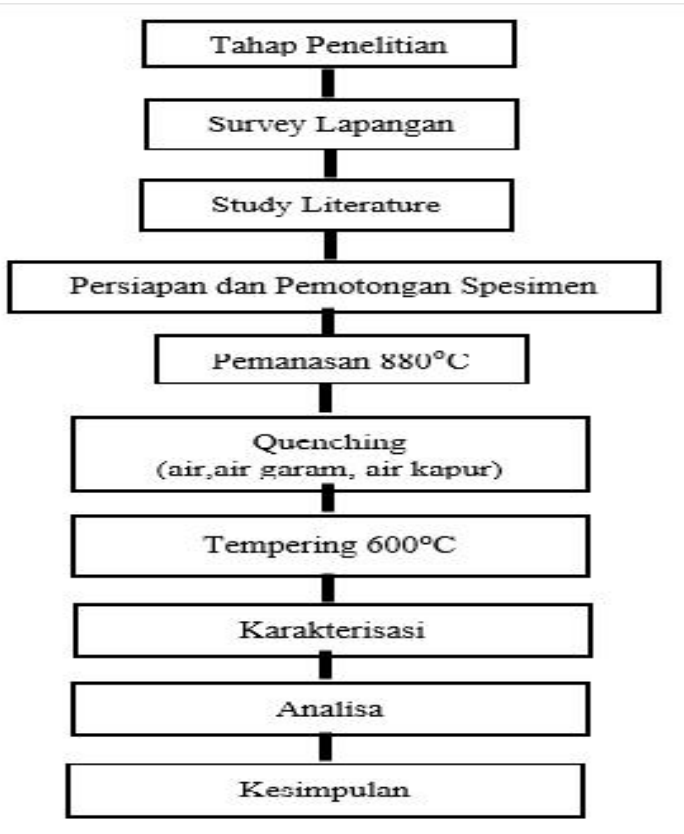

Gambar 3. Tahapan Penelitian.

\section{HASIL DAN PEMBAHASAN}

\section{Kekuatan Tarik}

Pada gambar 4 ditunjukan bahwa kekuatan tarik meningkat dangan perbedaan perlakuan hardenability. Kekuatan tarik tertinggi diperoleh dengan media pendingin air kapur yaitu $778 \mathrm{~N} / \mathrm{mm}^{2}$, sedangkan kekuatan tarik terendah dengan menggunakan air sebesar $686 \mathrm{~N} / \mathrm{mm}^{2}$. Tempering dengan menggunakan temperatur $600^{\circ} \mathrm{C}$ memberikan efek keuletan yang lebih tinggi.

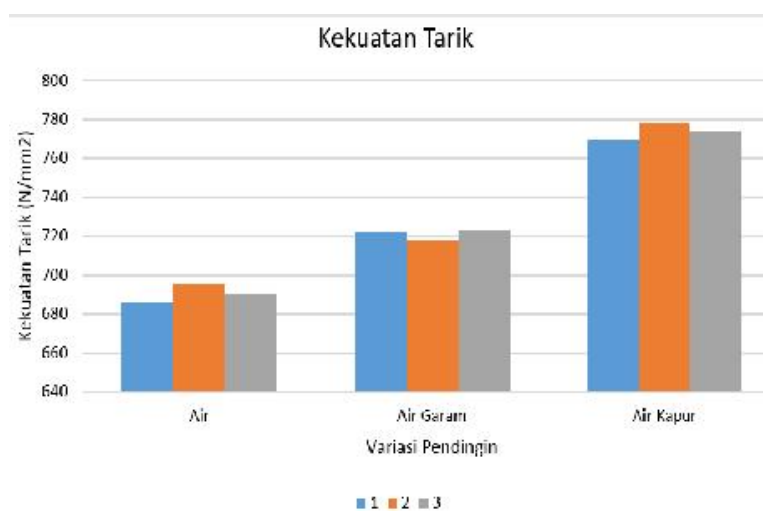

Gambar 4 Perbandingan kekuatan tarik pada perbedaan perlakuan hardenability.

\section{Kekuatan Luluh}

Pada gambar 5, menunjukan bahwa peningkatan kekuatan luluh dipengaruhi oleh variasi media hardenability. Diperoleh data bahwa dengan menggunakan media air kapur memiliki kekuatan luluh yang lebih tinggi $588 \mathrm{~N} / \mathrm{mm}^{2}, 617 \mathrm{~N} / \mathrm{mm}^{2}$ dan $579 \mathrm{~N} / \mathrm{mm}^{2}$ paling rendah dengan menggunakan media air biasa $528 \mathrm{~N} / \mathrm{mm}^{2}, 537 \mathrm{~N} / \mathrm{mm}^{2}$ dan 503 $\mathrm{N} / \mathrm{mm}^{2}$. 


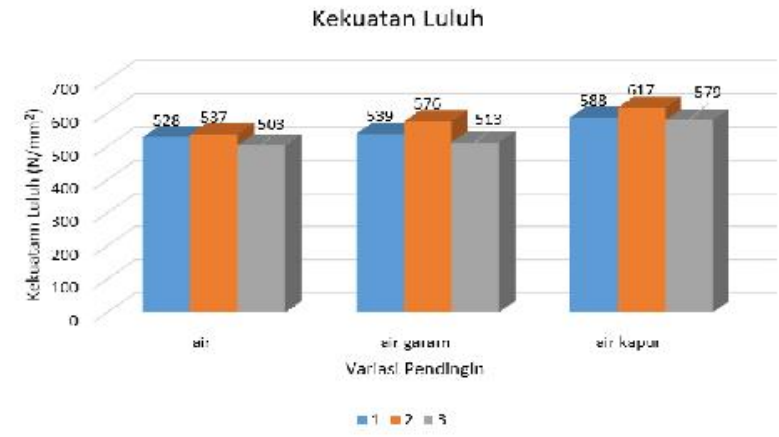

Gambar 5. Pengaruh media hardenability terhadap kekuatan luluh E355.

\section{Kekuatan Impak}

Pada gambar 6 menunjukan bahwa ketangguhan meningkat dengan perlakuan menggunakan media air kapur dimana ketangguhan tertinggi pada 216,222 dan $226 \mathrm{~J} / \mathrm{mm}^{2}$ dan terendah menggunakan media pendingin air $204,210,210 \mathrm{~J} / \mathrm{mm}^{2}$

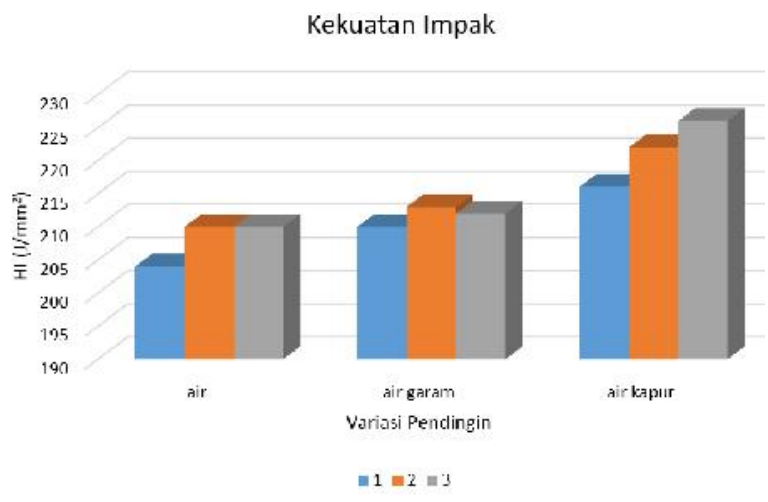

Gambar 6. Pengaruh perlakuan hardenability terhadap kekuatan impak

\section{KESIMPULAN}

Dari hasil data yang diperoleh dari pengaruh perbedaan perlakuan hardenability dan tempering pada sifat mekanik baja E355, kekuatan tarik dan kekuatan impak sebagai berikut : Perbandingan pada kekuatan tarik menunjukan bahwa kekuatan tarik pada hardenability dan tempering menggunakan air kapur memiliki kekuatan tarik tertinggi dengan kekuatan 770, 778 dan 774 N/mm². Pada kekuatan luluh juga menunjukan peningkatan, dan kekutan luluh tertinggi diperoleh dengan media air kapur sebesar $617 \mathrm{~N} / \mathrm{mm}^{2}$ dan terendah menggunakan air biasa sebesar $503 \mathrm{~N} / \mathrm{mm}^{2}$. Kekuatan impak tertinggi dihasilkan juga dengan hardenability menggunakan air kapur yaitu $216 \mathrm{~J} / \mathrm{mm}^{2}, 222 \mathrm{~J} / \mathrm{mm}^{2}, 226 \mathrm{~J} / \mathrm{mm}^{2}$ sedangkan terendah menggunakan air $204 \mathrm{~J} / \mathrm{mm}^{2}$, $210 \mathrm{~J} / \mathrm{mm}^{2}, 210 \mathrm{~J} / \mathrm{mm}^{2}$.

\section{DAFTAR PUSTAKA}

[1] Anggun, M., Pulun, K, K. \& Yayat, I, S., 2016, "Pengaruh Heat Treatmen Dengan Variasi Media Quenching Garam dan Oli Terhadap Struktur mikro dan Nilai Kekerasan Baja Pegas Daun AISI 6135", Jurnal Teori dan Aplikasi Fisika, Vol 4.

[2] Arief, M., 2012, "Pengaruh Quenching dan Tempering terhadap Kekerasan dan Kekuatan Tarik serta Struktur Mikro Baja Karbon Sedang untuk Mata Pisau Pemanan Sawit", Jurnal eDinamis, Vol II, ISSN 2338-1035

[3] AshishVerma., Pravin Kumar Singhba., 2013, "Influence of Heat Treatmen on Mechanical Properties of Aisi1040 Steel", JOSR-JMCE), Vol 10, PP 32-38.

[4] Assistant Prof. Dr. Zeyad D. Kadhim. 2016,"Effect of Quenching Media on Mechanical Properties for Medium Carbon Steel", Vol 6, ISSN 2248-9622.

[5] Djafrie., 1983, Teknologi Mekanik, Jilid 1, Erlangga., Indonesia.

[6] J, Kang., F, C, Zhang., X., W., Yang., B, Lv \& K. M. WU, 2017, "Effect of Tempering on the Microstructure and Mechanical Properties of a Medium Carbon Bainitic Steel", Materials Science \& Engineering A, S09215093(17)30053-9.

[7] M, A, A, Mohm Salleh., A, M, Mustafa Al Bakri., A, Alida, \& H, Kamarudin., 2013, "Effects of Seawater (Salt Water) to AISI 304 Mechanical Properties”, Australian Journal of Basic and Applied Sciences, ISSN 1991-8178.

[8] O, Bouaziz., H, Zurob \& M, Huang., 2013, "Driving Force and Logic of Development of Advance High Strenght Steels for Automotive Application”, Steel Research International, 937947.

[9] Panich, S., Barlat, F., Uthaisangsuk, V., Suranuntchai, S \& Jirathearanai., 2013, "Experimental and Theoritical Formability Analysis Using Strain and Stress Based Forming Limit Diagram for Advance High Strength Steel", Mater Des, 756-766.

[10] R. E Smallman and A, H, W, Ngan,, "Physical Metallurgy and Advance Materials", Seven Edition. 
[11] T, Sentilkumar1 \& T, K, Ajiboye., 2012, "Effect of Heat Treatmen Processes on the Mechanical Properties of medium Carbon Steel”. Journal of Minerals \& Materials Characterization \& Engineering, Vol 11, pp 143-152.

[12] Q, Hao., S. Qin., Y. Liu., X, Zuo., N, Chen \& Y, Rong., 2016, "Relation Between Microstructure and Formability of Quenching-PartitionTempering Martensitic Steel, Material Science \& Engineering A", S0921-5093(16)30679-7.

[13] W, Anggono., I, A, Shiahaan \& A. G. Cahyono., 2008, "Optimasi Proses Tempering Baja AISI 4140 Untuk Peningkatan Sifat Mekanik Roller Cyclo Speed Reducer". 